\title{
Developmental Trajectories of Social Withdrawal in the Transition from Childhood to Early Adolescence: The Effects of Intrusive Parenting and Peer Competence
}

\author{
Yoon Kyung Kim, Ju Hee Park \\ Department of Child \& Family Studies, Yonsei University, Seoul, Korea \\ 아동기에서 초기 청소년기로의 전환기 동안 사회적 위축 발달궤적에 \\ 미치는 부모의 과잉간섭의 영향과 또래유능성의 동시 및 지연효과 \\ 김윤경, 박주희 \\ 연세대학교 아동가족학과
}

\begin{abstract}
Objective: The purpose of this study was to examine the developmental trajectories of social withdrawal in the transition from childhood to early adolescence and to predict the effects of intrusive parenting and peer competence on the trajectories of social withdrawal.

Methods: Participants were 2,119 children from the Korean Children \& Youth Panel Survey [KCYPS]. Data from the 4th and 6th grade in elementary school, and from 7 th grade (1st grade in middle school) were used to analyze the developmental trajectory of social withdrawal. Intrusive parenting (4th grade) and peer competence (4th, 6th, and 7 th grades) were included as predictors.

Results: First, the social withdrawal increased during the transition from childhood to early adolescence. Additionally, the higher the intercept of social withdrawal, the more slowly social withdrawal increased. Second, the intercept of social withdrawal was found to be higher when social withdrawal (3rd grade) was higher, being higher in girls than in boys, and intrusive parenting was higher. The level of intrusive parenting had a negative influence on the slope of withdrawal. Third, peer competence reduced social withdrawal at that time, and peer competence of the previous period was shown to have a negative effect on the social withdrawal of the later period.

Conclusion: The results suggested that early interventions are needed to prevent social withdrawal during the transition from childhood to early adolescence. As also suggested, parents should encourage their child's independence from early childhood, for it is necessary in helping them learn peer interaction skills to reduce social withdrawal.
\end{abstract}

Keywords: social withdrawal, developmental trajectory, latent growth model, intrusive parenting, peer competence$$
\text { 서론 }
$$

성공적인 대인관계가 적응의 중요한 지표로 간주되는 현대 사

Corresponding Author: Ju Hee Park, Department of Child \& Family Studies, Yonsei University, 50, Yonsei-ro, Seodaemun-gu, Seoul, Korea E-mail: juheepark@yonsei.ac.kr
\end{abstract}

회에서 사회적 상황을 회피하고, 스스로를 고립시키는 행동 은 대표적인 심리사회적 부적응 행동 중 하나라고 할 수 있다. 사회적 위축은 타인과의 상호작용 기회를 의도적으로 피하

(C)The Korean Association of Child Studies

This is an Open Access article distributed under the terms of the Creative Commons Attribution Non-Commercial License (http:// creativecommons.org/licenses/by-nc/4.0) which permits unrestricted noncommercial use, distribution, and reproduction in any medium, provided the original work is properly cited. 
며, 사회적 상황에 적절히 참여하는 것에 어려움을 느끼고 자 주 고립된 행동을 보이는 것을 의미하는데(Rubin, Coplan, \& Bowker, 2009), 이는 우울, 불안, 외로움, 낮은 자아존중감 등 의 문제를 야기하는 것으로 보고되고 있다(Bowker, Rubin, \& Coplan, 2012; Goodwin, Fergusson, \& Horwood, 2004). 뿐만 아 니라 범죄 행동, 자살 시도, 인터넷 중독이나 은둔형 외톨이가 되는 등 심각한 사회적 부적응을 예측하는 요인으로도 작용할 수 있는데(Chan, 2015; Nelson, 2013), 이러한 사회적 위축의 부정적 결과들은 비단 성인에게만 국한되는 것이 아니다. 오 히려 아동기에는 대인 관계에서 필요한 사회적 기술과 규범을 습득하고 배워야 하는 시기로서 또래와의 경험을 통해 자기중 심적인 사고나 행동을 줄여가는 것이 중요한 발달과업이므로 또래 집단과 어울리지 못하는 등 타인과의 상호작용에 어려움 을 겪는 아동기의 사회적 위축 문제는 더욱 누적적이고 심각 한 결과를 초래할 수 있다.

더욱이 아동기에 경험하는 사회적 위축의 부정적 결과들은 시간이 경과함에 따라 사회적 위축을 더욱 안정적이고 지속적 이 되도록 만든다. 즉, 사회적으로 위축된 행동은 긍정적인 또 래 관계의 방해요인으로 작용하고, 이로 인한 또래 거부는 아 동을 사회적으로 더욱 위축되게 만드는 악순환을 거치게 된다. 이는 사회적으로 위축된 아동이 반복되는 또래 거부와 같은 사 회적 실패가 자신의 내적인 요소 때문이라고 믿게 되고, 시간 의 흐름에 따라 사회적 실패의 경험이 누적되면서 이러한 신념 과 불안이 강화되기 때문이라고 설명할 수 있다(Rubin, Bowker, $\&$ Kennedy, 2009). 아동기에 경험하는 사회적 위축의 장기적 영향에 관한 선행연구 결과에 따르면 아동이 경험하는 높은 수 준의 사회적 위축은 이후 청소년기에서의 부정적인 자기인식, 외로움, 우울, 불안 장애, 학교 공포증 등의 위험 요소가 되며 (Prior, Smart, Sanson, \& Oberklaid, 2000; Schwartz, Snidman, \& Kagan, 1999), 대부분 성인기까지 이어져 만성적인 심리적 어 려움을 야기할 수 있다(Oh et al., 2008). 이와 같은 연구 결과에 기초해 볼 때, 발달상의 연속적인 과정으로서의 사회적 위축의 발달궤적을 이해하고, 이러한 발달궤적에 영향을 미치는 요인 을 밝히는 것은 시간의 흐름에 따른 사회적 위축의 부정적 연 쇄를 막기 위한 방법을 강구하기 위해 반드시 필요하다.

아동의 사회적 위축에 영향을 미치는 환경적 요인은 다양 하지만, 여러 선행연구자들은 그 중에서도 부모의 양육행동과 아동의 또래 관계가 사회적 위축을 예측하는 데 있어서 중요 한 요인으로 작용함을 주장하였다. 이는 부모와 또래가 아동 기의 주요 사회적 상호작용 대상이기 때문이다. 먼저, 국내외 선행연구자들은 양육행동의 부정적 특성이 아동의 사회적 위
축에 영향을 미친다는 점을 경험적으로 검증해왔는데, 그 중 에서도 과잉간섭 양육행동은 사회적 위축과 밀접한 관련이 있 는 것으로 보고되고 있다(Coplan, Arbeau, \& Armer, 2008; Jeon \& Kim, 2016; Kiel, Premo, \& Buss, 2016). 과잉간섭 양육행동 이란 자녀의 개인적인 생활에 대해 부모가 지나치게 관여하고 제재를 가하는 것을 의미하는데(M. Huh, 2004), 이러한 양육 행동은 자녀가 스스로 결정하고 자율적으로 행동할 기회를 제 한함으로써 아동으로 하여금 사회적으로 위축되도록 만들 수 있다(Coplan et al., 2008). 또한, 과잉간섭 양육행동은 아동이 스스로 새로운 상황을 탐색하는 것을 어렵게 만들며, 대인 관 계에서의 문제를 자발적으로 해결하는 능력의 발달을 방해할 수 있다(Burgess, Rubin, Cheah, \& Nelson, 2001).

지금까지 다수의 연구들을 통해 한 시점에서 부모가 자녀 의 생활에 과도하게 관여하고 간섭할수록 해당 시기에서 아동 의 사회적 위축 수준이 높아짐을 아는 데 도움이 되었다. 하지 만 부모의 과잉간섭이 시간의 흐름에 따른 아동의 사회적 위 축 발달에 미치는 영향을 이해하는 데는 제한적이었다. 부모 의 과잉간섭 양육행동은 사회적 위축의 종단적인 발달에 영향 을 미칠 수 있으며, 이는 양육행동의 안정적인 속성과 관련지 어 생각해볼 수 있다. 과잉간섭 양육행동을 비롯한 부모의 양 육행동은 부모가 자녀를 양육하는 데 있어 일반적이고 안정 적으로 나타나는 행동을 의미하므로(Huh, 2004) 시간의 흐름 에 따라 안정적인 개념(Forehand \& Jones, 2002)으로 간주할 수 있다. 과잉간섭 행동의 안정적 속성을 고려했을 때 한 시점에 서의 부모의 과잉간섭이 아동의 사회적 위축에 미치는 영향 은 해당 시기에 나타나기도 하지만 시간의 흐름에 따른 사회 적 위축의 발달에 지속적으로 영향을 미칠 수 있다. 실제로 국 외 선행연구(Booth-LaForce, Oh, Kennedy, Rubin, Rose-Krasnor, \& Laursen, 2012)에서 아동이 11세 일 때 부모의 높은 수준의 과잉간섭은 11 세에서 14 세 동안 사회적 위축 수준의 증가를 예측하였다. 이를 통해 부모의 과잉간섭은 안정적 속성으로써 사회적 위축의 종단적인 발달에 영향을 미칠 수 있는 요인으 로 볼 수 있다.

다른 한편으로는 학령기가 또래와 함께 집단을 형성하며 상호적인 정서적 교류와 지지를 본격적으로 시도하게 되는 시 기이기 때문에 아동의 또래 관계는 사회적 위축을 예측하는 또 다른 중요한 요인이 될 수 있다. 실제로 아동의 또래 관계 특성과 사회적 위축 간의 관계를 검증한 국내외 선행연구 결 과에 따르면 친한 친구와의 관계에서 갈등과 불만족감을 느 끼는 것과 같은 낮은 우정의 질, 또래와 상호작용하는 능력의 부족, 또래로부터의 거부와 괴롭힘 등은 아동의 사회적 위축 
을 직접 야기하는 요인으로 작용하는 것으로 나타난 바 있다 (Coplan \& Armer, 2007; W.-H. Min \& Son, 2017). 그 중에서도 또래와의 관계를 효과적으로 형성하고 유지하며, 또래 관계 내 에서 적합한 방식으로 자신의 목표를 달성하는 능력인 또래유 능성(J. H. Park \& Rhee, 2001b)이 낮은 아동의 경우, 사회적 위 축의 수준이 높은 것으로 나타났다(Kingery, Erdley, Marshall, Whitaker, \& Reuter, 2010; J. Y. Park, Kang, Heo, \& Jung, 2010; Wu, Lo, Feng, \& Lo, 2010). 또래유능성이 아동의 사회적 위축 에 미치는 영향을 살펴보면, 또래유능성이 낮은 아동들은 또 래 관계에서 자신의 생각이나 의견을 정확하게 표현하거나 또 래의 요구를 이해하기 힘들며, 또래에게 적절하게 반응하는 것 을 어려워하는 경향이 있다. 이러한 아동들은 또래와 상호작 용 하는 데 어려움을 겪을 수 있으며, 이러한 어려움은 또래와 만족스러운 우정을 형성하거나 유지할 수 있는 기회를 제한하 게 되고, 결과적으로 아동의 사회적 위축에 영향을 미칠 수 있 다(Bornstein, Hahn, \& Haynes, 2010; Segrin \& Flora, 2000). 다시 말해서, 원만한 또래 관계의 형성과 유지에 필요한 능력이 부 족한 아동들은 그 결과로서 또래들과 상호작용하는 상황에서 사회적으로 위축이 될 가능성이 높아지게 되는 것이다.

그러나 사회적 위축을 예측하는 또래유능성은 아동이 가지 고 있는 기술이나 행동 특성 자체인 개인의 안정적인 특성으 로서도 중요하지만 상호작용하는 또래가 누구냐에 따라 변화 되는 경우가 있다. 따라서 사회적 위축에 영향을 미치는 또래 유능성은 개인의 안정적 특성뿐 아니라 누구와 또래 관계를 형 성하느냐에 따라 다소 달라질 수 있음을 고려해야 한다. 특히, 초등학교에서 중학교로 넘어가는 아동기에서 초기 청소년기 로의 과도기적 전환기 동안 아동은 상급 학교로의 진입과 함 께 친숙하지 않은 많은 또래들과의 만남이 있으며, 이미 친숙 했던 또래들이 같은 학교로 진급했을지라도 교실 내에서 새로 운 또래 조합들이 생길 수 있으므로(Shell, Gazelle, \& Faldowski, 2014), 전환기 동안 학년이 변함에 따라 아동의 또래유능성 수 준에 차이가 있을 수 있다는 점을 고려해야 할 것이다.

종합해보면, 다수의 선행연구들은 부모의 과잉간섭 양육행 동과 또래유능성은 학령기 아동의 사회적 위축에 영향을 미친 다는 결과를 보고해 왔으나, 이러한 연구의 대부분은 특정 시 점에서의 부모의 과잉간섭과 또래유능성이 사회적 위축에 미 치는 영향을 횡단 자료로 분석한 것이었다. 따라서 시간의 경 과에 따른 사회적 위축의 변화 양상을 파악하는 데 어려움이 있으며, 과잉간섭과 또래유능성이 사회적 위축의 변화에 어떻 게 영향을 미치는지를 이해하는 데에는 제한적이었다. 뿐만 아 니라 아동기나 청소년기 중 어느 한 발달 단계에만 초점을 둘
경우, 아동기에서 초기 청소년기로의 전환기동안 사회적 위축 의 발달궤적의 변화를 분석하기 어렵기 때문에 부모의 과잉간 섭과 또래유능성이 전환기 동안 사회적 위축의 종단적인 발달 에 어떤 영향을 미치는지를 이해하는 것에는 한계가 있었다.

다시 말해서 아동기에서 초기 청소년기로의 전환기, 즉 초 등학교에서 중학교로 전환하는 시기의 사회적 위축의 발달 양 상과 이에 영향을 미치는 요인에 주목해야할 필요가 있는데, 이는 중학교라는 상급 학교로 진학함으로써 낮선 생활을 시작 하고, 새로운 또래들을 만나게 되는 것과 같은 큰 환경적인 변 화를 경험함과 동시에 사춘기로 인한 신체적, 심리적 변화도 함께 겪는 과도기적인 불안정 시기로서 다른 발달적 시기에 비 해 사회관계에서 더 큰 어려움을 경험할 가능성이 높기 때문이 다(Yoo, 2007). 몇몇 국외 연구(Booth-LaForce et al., 2012; Miers, Blöte, Heyne, \& Westenberg, 2014)에서 아동기에서 초기 청소년 기로의 전환과 함께 사회적 위축이 증가하는 것으로 나타난 결 과 역시 초등학교에서 중학교로의 전환기 동안 사회적 위축을 예방하거나 감소시키기 위한 효과적인 개입 방안의 마련이 매 우 중요함을 시사하고 있다. 전환기 동안의 사회적 위축 발달 에 영향을 미치는 부모의 과잉간섭과 또래유능성의 영향을 이 해함으로써 사회적 위축 문제를 해결하기 위한 효과적인 개입 방법과 시기를 정하는 데 도움을 얻을 수 있을 것이다.

이상과 같은 연구의 필요성에 근거하여 본 연구에서는 초 등학교에서 초기 청소년기로의 전환기 동안의 사회적 위축 발 달궤적을 알아보고, 사회적 위축의 발달궤적에 영향을 미치 는 요인으로 부모의 과잉간섭과 또래유능성의 영향을 검증 하고자 한다. 이 때 전환기 동안의 사회적 위축 발달궤적을 알 아보기 위해 초등학교 중기, 초등학교 후기, 중학교 초기에서 의 사회적 위축을 분석하였는데, 각 시기마다 아동의 심리적 인 특성, 부모에 대한 의존과 독립의 욕구, 환경 변화 측면에 서 과도기적 특성을 보여주고 있기 때문이다. 즉, 초등학교 중 기는 최근 아동과 청소년의 발달이 저연령화 되어 성장과 발 달이 가속화됨으로써 신체적이고 심리적인 변화가 동반되는 사춘기가 시작되는 시점이며(M. Shin, Jeon, \& Yoo, 2012), 또 래 집단에서의 소속감을 중요하게 인식하기 시작하는 시기이 므로 아동기에서 초기 청소년기로의 전환이 시작되는 시기로 볼 수 있다. 초등학교 후기는 이전 시기와 다르게 부모에 대한 의존성이 크게 줄어들면서 자율성과 정서적 독립을 시작하며 (Kang, Kim, Song, Sim, \& Kim, 2007), 상급 학교로의 진학을 앞두고 있는 시기이다. 그리고 중학교 초기의 경우, 상급 학교 로 진학함과 동시에 새로운 환경과 교사나 또래 관계에 적응 을 해야 하는 시기이다. 이에 본 연구에서는 전환기의 사회적 
Table 1

Waves of the Variables Used in the Analysis

\begin{tabular}{|c|c|c|c|c|}
\hline & 3rd wave & 4th wave & 6th wave & 7th wave \\
\hline Social withdrawal & & O & O & O \\
\hline Intrusive parenting & & O & & \\
\hline Peer competence & & O & O & O \\
\hline Control variable (Social withdrawal reported by parent) & O & & & \\
\hline
\end{tabular}

위축 발달궤적을 알아보기 위해 초등학교 중기, 초등학교 후 기, 중학교 초기에 해당하는 시기인 초등학교 4학년, 초등학교 6학년, 중학교 1학년의 사회적 위축 측정치를 포함시켰다. 한 편, 자녀에 대한 부모의 안정적인 행동으로 나타는 과잉간섭 양육행동(Zhang, Wei, Ji, Chen, \& Deater-Deckard, 2017)은 시 간의 흐름에 따라 안정적인 속성으로 간주하여 한 시점의 측 정치만 사용하였다. 반면, 또래유능성의 경우 상호작용대상인 또래 집단의 특성이 반영되어(N. Shin et al., 2011) 측정 시기에 따라 차이가 있을 것이라고 판단되었기 때문에 사회적 위축이 측정된 시기의 측정치를 모두 포함시켜서 사회적 위축에 미 치는 동시 효과와 지연 효과를 분석하였다. 또한, 아동의 사회 적 위축의 안정적인 속성을 고려하고(Oh et al., 2008), 사회적 위축이 아동의 성에 따라 달라질 수 있다는 선행연구 결과들 (Shim, 2010; Sterba, Prinstein, \& Cox, 2007)에 기초하여 초등학 교 3학년 당시 부모의 보고에 의한 사회적 위축 측정치와 아동 의 성을 통제 변인으로 포함시키고자 하였다.

본 연구의 결과는 부모의 과잉간섭 양육행동과 또래유능성 이 사회적 위축의 발달궤적에 미치는 영향을 알아봄으로써 초 기 청소년기로의 전환기 동안 사회적 위축을 예방하고, 사회 적 위축 문제가 유발할 수 있는 부정적인 결과들의 시간의 흐 름에 따른 누적적 영향을 감소시키기 위하여 부모와 또래 관 계를 통해 어떠한 개입을 제공할지에 관련된 정보를 제공해줄 수 있을 것이다. 이상의 연구 목적을 위해 본 연구에서 설정한 연구문제는 다음과 같다.

\section{연구문제 1}

아동기에서 초기 청소년기로의 전환기 동안 사회적 위축의 발달궤적은 어떠한가?

\section{연구문제 2}

아동기에서 초기 청소년기로의 전환기 동안 사회적 위축의 발달궤적에 미치는 부모의 과잉간섭의 영향과 또래유능성의 동시 효과와 지연 효과는 어떠한가?

\section{연구방법}

\section{연구대상}

본 연구는 한국청소년정책연구원에서 2010년에 초등학교 1 학년 학생들을 대상으로 2016년 중학교 1학년까지 매년 추적 조사를 실시한 한국아동.청소년패널조사(Korean Children \& Youth Panel Survey [KCYPS])의 자료를 사용하였다. 본 연구에 서 초등학교 중기, 후기, 중학교 초기의 각 시기마다 특징적으 로 나타나는 아동의 심리적인 특성, 부모에 대한 의존과 독립 에 대한 요구, 환경에서의 변화들이 과도기적 특성을 보여주 고 있다는 것을 근거로 초등학교 중기, 후기, 중학교 초기를 통 해 전환기 동안의 사회적 위축을 알아보고자 조사되지 않은 초등학교 5학년 자료(5차)를 제외하고 초등학교 중기, 후기, 중학교 초기를 대표하는 시기로 초등학교 4학년, 6학년, 중학 교 1학년의 세 시점 자료를 활용하였다. 예측 변인으로 과잉간 섭 양육행동은 4학년, 또래유능성은 4학년, 6학년, 중학교 1학 년 자료를 사용하였으며, 통제 변인으로 아동의 성과 초등학 교 3학년 때 부모 보고로 측정된 사회적 위축 자료를 사용하 였으며, 분석에 사용된 변인들의 측정 시기는 Table 1 에 제시 되었다. 본 연구에서 자료 분석에 사용된 대상은 초등학교 4 학년에 수집된 자료를 기준으로 총 2,11 명이며, 남아 1,093 명 (46.7\%), 여아 1,026명(43.8\%)으로 구성되었다.

\section{연구도구}

\section{아동의 사회적 위축}

아동의 사회적 위축은 Kim과 $\operatorname{Kim}$ (1998)의 척도를 기초로 한 국아동청소년 패널 조사에서 수정한 도구로 측정되었다. 이 척도는 아동의 자기보고식 척도이며, 총 5 개 문항으로 구성되 어 있다. 사회적 위축은 다양한 사회적 상황에서 수줍음을 느 끼고 우울해지고 그러한 상황을 피하는 경향이나 행동을 의미 
하며, 문항 내용을 살펴보면 “주위에 사람들이 많으면 어색해 한다.”, "부끄럼을 많이 탄다.”, "다른 사람들에게 자신의 의견 을 분명하게 말하기 어려워한다.”, “수줍어한다.”, “사람들 앞 에 나서기를 싫어한다."이다.

응답자는 총 5 개의 문항에 대해 동의하는 정도에 따라 매우 그렇다(1점)에서 전혀 그렇지 않다(4점)까지 4점 리커트 척도 에 응답하도록 되어 있으며, 모든 문항은 역채점되었다. 가능 한 총점 범위는 5점 20점이며, 점수가 높을수록 사회적 위축 의 수준이 높음을 의미한다. 본 연구에서 초등학교 4학년, 6 학 년, 중학교 1학년 시기에 측정된 문항 내적 합치도 Cronbach's $\alpha$ 는 $.86, .88, .89$ 였다. 한편, 본 연구에서 통제 변인으로 포함시 킨 초등학교 3 학년 시기의 사회적 위축은 동일한 척도로 부모 에 의해 측정되었으며, 문항 내적 합치도 Cronbach's $\alpha$ 는 .90이 었다.

\section{부모의 과잉간섭 양육행동}

부모의 과잉간섭 양육행동을 측정하기 위해 사용된 도구는 한 국아동청소년 패널 조사에서 수정하고 보안한 Huh (2004)의 '부모 양육행동척도' 중 부모의 과잉간섭 문항이었다. 이 척도 는 아동이 자기보고식으로 응답하게 되어 있으며, 총 4 개 문항 에 대해 지난 일 년 간 부모가 아동의 개인적인 생활에 대해 어 느 정도 관여하고 간섭했는지를 평정하도록 되어 있다.

문항의 예로는 "작은 일에 대해서도 이래라 저래라 간섭하 신다.”, “보통 아이들이 할 수 있는 일도 불안해하시며 내게는 못 하게 하신다.” 등이 있다. 각 문항은 문항 내용에 동의하는 정도에 따라 매우 그렇다(1점)에서 전혀 그렇지 않다(4점)까 지 4점 리커트 척도 방식으로 응답하도록 되어 있으며, 모든 문항은 역채점되었다. 가능한 총점 범위는 4점 16점이며, 점 수가 높을수록 부모가 자녀의 개인적인 생활에 대해 지나치게 관여하고 제재를 가하고 있음을 의미한다. 문항 내적 합치도 Cronbach's $\alpha$ 는 .69였다.

\section{아동의 또래유능성}

또래 관계에서 보이는 아동의 유능성은 B. S. Min (1991)이 제 작한 초등학생용 학교생활적응척도의 문항을 한국아동청소 년 패널 조사에서 수정하고 번안한 척도 중 교우관계에 관련 된 문항을 사용하여 측정되었다. 본 연구에서는 교우관계 5 개 문항 중 “친구가 하는 일을 방해한다.”를 제외하고 총 4 개 문 항을 사용하였다. 그 이유는 또래 관계에서 문제를 경험하지
않는 것이 곧 유능함을 의미하는 것이 아니므로 부정적 특성 을 또래유능성의 평가 기준으로 삼는 것은 적절하지 못하기 때문이다(J. H. Park \& Rhee, 2001a). 실제로 주성분 분석을 이 용하고 Oblimin을 적용하여 요인 분석을 실시한 결과 이 문항 은 한 개 요인으로 묶이지 않아 최종적으로 제외하였다. 본 연 구에서 사용된 문항의 예는 “우리 반 아이들과 잘 어울린다.", "놀이나 모둠활동을 할 때 친구들이 내 말을 잘 따라 준다." 등 이다.

이 척도는 자기보고식 척도로 각 문항은 매우 그렇다(1점) 에서 전혀 그렇지 않다(4점)까지 4점 리커트 척도에 응답하도 록 되어 있다. 가능한 총점 범위는 4점 16점이며, 점수가 높 을수록 아동이 원만한 또래 관계를 형성하고 유지하는 데 필 요한 능력이 우수함을 의미한다. 문항 내적 합치도 Cronbach's $\alpha$ 는 .74, .73, .73이었다.

\section{자료분석}

SPSS 24 를 이용하여 연구 변인의 기술통계분석과 상관관계분 석을 실시하였다. 그 다음으로 초등학교 4학년, 6학년, 중학교 1 학년 동안 사회적 위축의 종단 변화에 대한 발달궤적을 확인 하고, 부모의 과잉간섭 양육행동과 또래유능성이 사회적 위 축 발달궤적에 미치는 영향을 알아보기 위해 Mplus 8 (Muthén \& Muthén, 1998-2002) 프로그램으로 사회적 위축의 잠재성장 모형(Latent Growth Modeling [LGM])을 적용하여 분석하였다. 구체적인 분석 절차는 다음과 같다.

첫째, 잠재성장모형을 활용하여 사회적 위축 변인만 을 포함한 모형의 발달궤적을 추정하기 위해 무조건 모형 (unconditional model)을 분석하였다. 본 연구에서 모형 적합 도 평가를 위해 TLI, CFI, RMSEA를 사용하였다. 일반적으로 TLI, CFI는 .95 이상, RMSEA는 .05 이하면 모형 적합도가 좋 은 것으로 간주된다(Keith, 2015). 이 기준에 기초하여 모형 적 합도 평가 결과, 모형이 양호하다고 판단되어 개인 간 초기값 과 변화율의 변량이 유의한 차이를 보이는지 확인하였다. 둘 째, 사회적 위축의 발달궤적을 설명하는 예측 요인을 알아보 기 위해 앞서 채택한 무조건 모형에서 통제 변인과 예측 변인 들을 추가한 조건 모형(conditional model) 분석을 실시하였다. 또래유능성의 경우, 전환기 동안 학년의 변화에 따라 달라질 수 있는 개념으로 간주하여 시간의 흐름에 따라 사회적 위축 의 발달궤적에 미치는 동시 및 지연효과를 분석하였다. 


\section{연구결과}

\section{주요 변인들의 기초 통계}

본 연구에서 사용된 사회적 위축, 부모의 과잉간섭 양육행동, 아동의 또래유능성의 평균과 표준편차 등 기술통계치는 Table 2 에 제시된 바와 같다. 사회적 위축의 평균은 4학년 $9.64(S D=$ $3.61)$, 6학년 $10.48(S D=3.76)$, 중학교 1학년 $10.63(S D=3.82)$ 으로 나타났다. 예측 변인 중 4학년 때 측정한 부모의 과잉간 섭 양육행동의 평균은 $10.37(S D=3.27)$ 이며, 또래유능성의 경 우 초등학교 4학년, 6학년, 중학교 1학년 시기의 측정치 평균 은 각각 $13.00(S D=2.16), 13.01(S D=1.90), 13.09(S D=1.82)$ 였다.
기초 분석을 하여 상관분석을 실시한 결과는 Table 3에 제 시하였다.

\section{사회적 위축의 발달궤적(무조건 모형)}

본 연구는 아동기에서 초기 청소년기로의 전환기 동안 사회 적 위축의 변화를 추정하고, 이에 대한 개인차를 검증하기 위 해 잠재성장모형을 사용하였다. 아동의 사회적 위축 발달궤 적을 예측하기 위한 예측 요인을 모형에 투입하기 전에 사회 적 위축만을 투입한 무조건 모형을 분석하였다. 무조건 모형 은 Figure 1에 제시하였으며, 무조건 모형의 적합도는 $\chi^{2}=5.78$ $(p=0.016), \mathrm{RMSEA}=.047, \mathrm{CFI}=.995, \mathrm{TLI}=.986$ 으로 나타나 우수한 수준의 적합도를 보여주었다.

Table 2

Means and Standard Deviations of Variables

\begin{tabular}{|c|c|c|c|}
\hline Variables & Score range & $M$ & $S D$ \\
\hline Social withdrawal (4th in elementary school) & $5 \sim 20$ & 9.64 & 3.61 \\
\hline Social withdrawal (6th in elementary school) & $5 \sim 20$ & 10.48 & 3.76 \\
\hline Social withdrawal (1st in middle school) & $5 \sim 20$ & 10.63 & 3.82 \\
\hline \multicolumn{4}{|l|}{ Predictor } \\
\hline Intrusive parenting (4th in elementary school) & $4 \sim 16$ & 10.37 & 3.27 \\
\hline Peer competence (4th in elementary school) & $4 \sim 16$ & 13.00 & 2.16 \\
\hline Peer competence (6th in elementary school) & $4 \sim 16$ & 13.01 & 1.90 \\
\hline Peer competence ( 1 st in middle school) & $4 \sim 16$ & 13.09 & 1.82 \\
\hline \multicolumn{4}{|l|}{ Control variables } \\
\hline Social withdrawal (3rd in elementary school) & $5 \sim 20$ & 8.79 & 2.78 \\
\hline Children's gender (dummy variable) & 0 or 1 & 8.52 & .50 \\
\hline
\end{tabular}

Note. $N=2119 .{ }^{\text {a }}$ girl $=0$, boy $=1$.

Table 3

Correlations Among Variables

\begin{tabular}{|c|c|c|c|c|c|c|c|c|c|}
\hline & 1 & 2 & 3 & 4 & 5 & 6 & 7 & 8 & 9 \\
\hline 1. Social withdrawal (4th) & - & & & & & & & & \\
\hline 2. Social withdrawal (6th) & $-.43^{* *}$ & - & & & & & & & \\
\hline 3. Social withdrawal (7th) & $-.32^{* *}$ & $-.53^{* *}$ & - & & & & & & \\
\hline 4. Social withdrawal (3rd) & $-.26^{* *}$ & $-.25^{* *}$ & $-.24^{* *}$ & - & & & & & \\
\hline 5. Children's gender & $-.03^{* *}$ & $-.07^{* *}$ & $-.02^{* *}$ & $-.08^{* *}$ & - & & & & \\
\hline 6. Intrusive parenting ( $4 \mathrm{th})$ & $-.11^{* *}$ & $-.06^{* *}$ & $-.05^{* *}$ & $-.05^{* *}$ & $-.16^{* *}$ & - & & & \\
\hline 7. Peer competence (4th) & $-.28^{* *}$ & $-.18^{* *}$ & $-.15^{* *}$ & $-.07^{* *}$ & $-.09^{* *}$ & $-.05^{*}$ & - & & \\
\hline 8. Peer competence (6th) & $-.19^{* *}$ & $-.33^{* *}$ & $-.25^{* *}$ & $-.10^{* *}$ & $-.02^{* *}$ & $-.07^{* *}$ & $-.39^{* *}$ & - & \\
\hline 9. Peer competence $(7 \mathrm{th})$ & $-.15^{* *}$ & $-.25^{* *}$ & $-.34^{* *}$ & $-.09^{* *}$ & $-.00^{* *}$ & $-.05^{*}$ & $-.27^{* *}$ & $-.42^{* *}$ & - \\
\hline
\end{tabular}

Note. $3 \mathrm{rd}=3 \mathrm{rd}$ grade in elementary school; $4 \mathrm{th}=4$ th grade in elementary school; $6 \mathrm{th}=6$ th grade in elementary school; 7 th $=1$ st grade in middle school.

${ }^{*} p<.05 .{ }^{* *} p<.01$. 


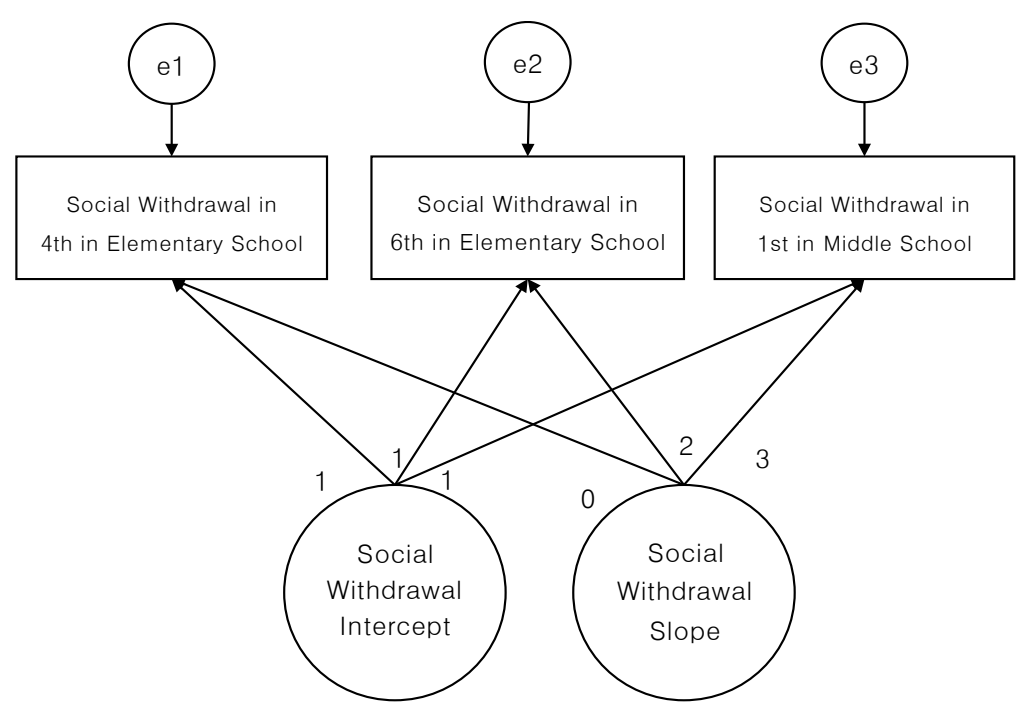

Figure 1. Developmental trajectory model of social withdrawal (unconditioned model).

Table 4

Latent Growth Model Estimates of Social Withdrawal (Unconditioned Model)

\begin{tabular}{cccccc}
\hline & \multicolumn{2}{c}{ Intercept } & \multicolumn{2}{c}{ Slope } & Covariance \\
\cline { 2 - 5 } & $M$ & Variance & $M$ & Variance & Intercept $\leftrightarrow$ Slope \\
\hline Social withdrawal & $9.67^{* * *}$ & $8.83^{* * *}$ & $.34^{* * *}$ & $1.03^{* * *}$ & $-1.50^{* * *}$ \\
\hline
\end{tabular}

${ }^{* * *} p<.001$.

사회적 위축에 대한 무조건 모형 검증 결과는 Table 4에 제 시된 바와 같다. 사회적 위축의 초기치 평균이 9.67 , 변화율 평 균이 .34로 모두 통계적으로 유의하였으며, 이는 초등학교 4학 년 아동이 한 학년 올라갈 때, 사회적 위축은 평균 .34씩 증가 했음을 나타낸다. 또한, 초기치와 변화율의 부적 상관계수 $(r$ $=-1.50, p<.001)$ 는 사회적 위축의 초기치가 높을수록 사회적 위축은 천천히 증가함을 보여준다. 초기치와 변화율의 분산은 각각 8.83과 1.03 으로 모두 통계적으로 유의하게 나타나 사회 적 위축의 발달궤적에서 개인차가 유의함을 보여주었다.

무조건 모형의 검증 결과는 초등학교 4학년 아동의 사회적 위축에는 개인 간 차이가 있으며, 초등학교 4학년부터 중학교 1 학년까지 사회적 위축이 증가하는 경향이 있고, 그 변화의 정 도에는 개인차가 있는 것으로 나타나 개인차의 예측 요인이 될 수 있는 변인을 투입한 추가 분석의 근거를 제공해주었다.

\section{사회적 위축의 발달에 미치는 부모의 과잉간섭 의 영향과 또래유능성의 동시 및 지연 효과}

위의 무조건 모형 검증 결과 사회적 위축의 초기값과 변화율
의 분산이 유의한 것으로 나타났는데, 이는 개인 간에 사회적 위축의 초기 값과 변화 속도가 다르다는 것을 의미한다. 이러 한 개인차를 설명하기 위하여 무조건 모형에 사회적 위축 발 달궤적의 예측 변인인 부모의 과잉간섭과 또래유능성을 추가 한 조건 모형을 설정하였다. 조건 모형의 적합도 지수들은 $\chi^{2}$ $=14.976(p=0.020), \mathrm{RMSEA}=.027, \mathrm{CFI}=.995, \mathrm{TLI}=.982$ 로 나타나 모형 적합도는 우수한 수준임을 보여주었다.

Table 5에 제시된 바와 같이 사회적 위축 발달궤적에 대한 각 변인들의 영향력을 살펴보면, 사회적 위축의 초기치에 대해 서 통제 변인으로 투입된 아동의 성 $(B=-.41)$ 과 3 학년 때 부모 가 보고한 아동의 사회적 위축 $(B=.25)$ 은 유의한 영향을 미친 것으로 나타났다. 또한 예측 변인으로 부모의 과잉간섭 양육 행동 $(B=.12)$ 역시 사회적 위축의 발달궤적에 유의하게 영향을 미쳤다. 즉, 여아가 남아보다, 3 학년 때의 사회적 위축 수준이 높을수록, 그리고 부모의 과잉간섭이 높을수록 아동의 사회적 위축 초기값이 높았다. 또한, 사회적 위축의 변화율에 대한 예 측 요인으로 부모의 과잉간섭 $(B=-.03)$ 이 유의한 영향을 미치 는 것으로 나타났는데, 이는 4학년 당시 부모의 과잉간섭 수준 이 높을수록 사회적 위축이 더 느리게 증가함을 의미한다. 
Table 5

Predictive Effects of Latent Growth Model

\begin{tabular}{|c|c|c|c|}
\hline & $B$ & $S E$ & $\beta$ \\
\hline Social withdrawal $(3 \mathrm{rd}) \longrightarrow$ Intercept of social withdrawal & $-.25^{* * *}$ & .02 & $-.30^{* * *}$ \\
\hline Children's gender $\rightarrow$ Intercept of social withdrawal & $-.41^{* * *}$ & .15 & $-.08^{* * *}$ \\
\hline Intrusive parenting (4th) $\rightarrow$ Intercept of social withdrawal & $-.12^{* * *}$ & .23 & $-.12^{* * *}$ \\
\hline Social withdrawal $(3 \mathrm{rd}) \rightarrow$ Slope of social withdrawal & $-.00^{* * *}$ & .01 & $-.02^{* * *}$ \\
\hline Children's gender $\rightarrow$ Slope of social withdrawal & $-.08^{* * *}$ & .06 & $-.05^{* * *}$ \\
\hline Intrusive parenting $(4 \mathrm{th}) \rightarrow$ Slope of social withdrawal & $-.03^{* * *}$ & .03 & $-.09^{* * *}$ \\
\hline Peer competence $(4 \mathrm{th}) \rightarrow$ Social withdrawal (4th) & $-.43^{* * *}$ & .03 & $-.26^{* * *}$ \\
\hline Peer competence $(4 \mathrm{th}) \rightarrow$ Social withdrawal (6th) & $-.09 * * *$ & .03 & $-.05^{* * *}$ \\
\hline Peer competence $(6 \mathrm{th}) \rightarrow$ Social withdrawal (6th) & $-.57^{* * *}$ & .04 & $-.29^{* * *}$ \\
\hline Peer competence $(6 \mathrm{th}) \longrightarrow$ Social withdrawal $(7 \mathrm{th})$ & $-.23^{* * *}$ & .05 & $-.12^{* * *}$ \\
\hline Peer competence $(7 \mathrm{th}) \rightarrow$ Social withdrawal $(7 \mathrm{th})$ & $-.54^{* * *}$ & .04 & $-.26^{* * *}$ \\
\hline
\end{tabular}

Note. 3rd $=3$ rd in elementary school; 4 th $=4$ th in elementary school; 6th $=6$ th in elementary school; 7 th $=1$ st in middle school. ${ }^{*} p<.05{ }^{* *} p<.01{ }^{* * *} p<.001$.

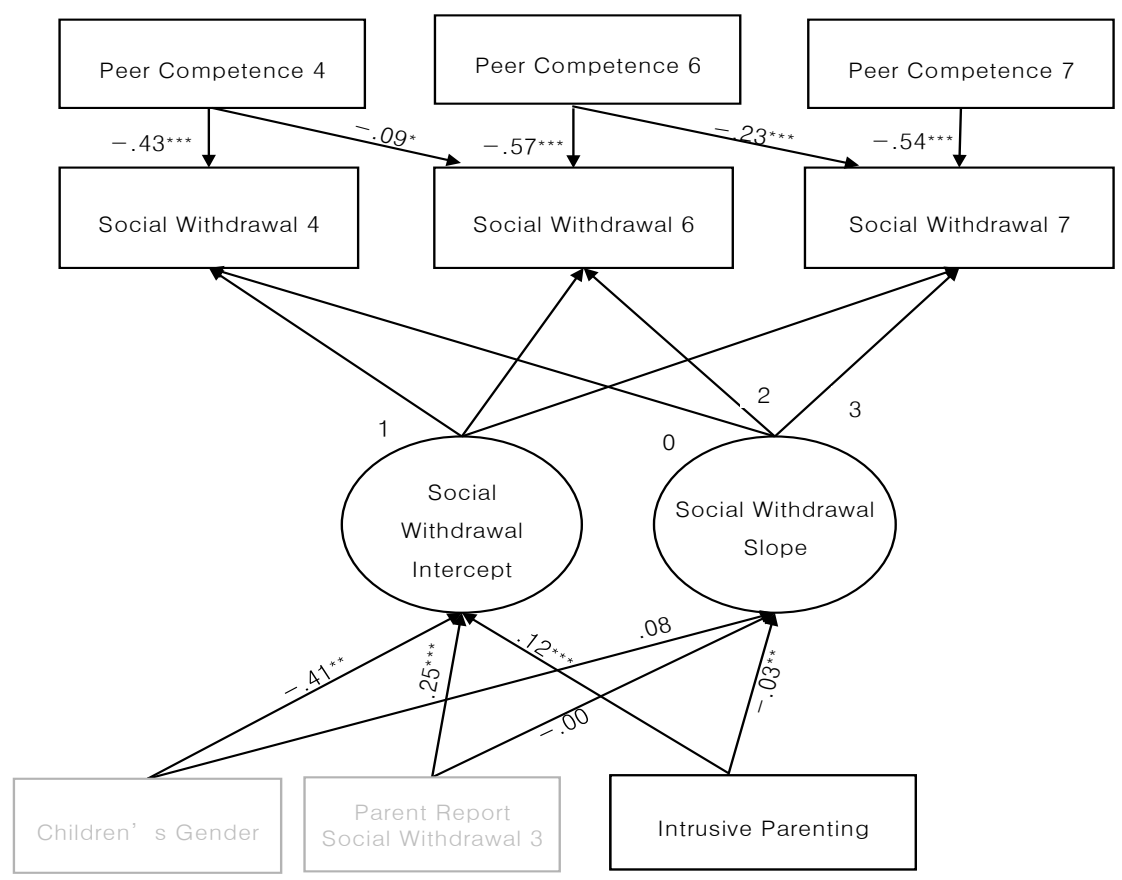

Figure 2. Effect of intrusive parenting and peer competence on the developmental trajectory of social withdrawal. Control variables are children's gender and parent report social withdrawal 3.

${ }^{*} p<.05 .{ }^{* *} p<.01 .{ }^{* * *} p<.001$.

다음으로, 사회적 위축에 영향을 미치는 또래유능성의 동 시 및 지연효과를 검증한 결과, 모든 경로계수가 부적인 것으 로 나타났으며, 세 시기 모든 또래유능성의 지연효과는 동시 효과보다 그 크기가 작았다. 우선 동시효과를 살펴보면 4학년, 6 학년, 중학교 1 학년에서의 또래유능성은 모두 같은 시기 사 회적 위축〔(4학년: $B=-.43),(6$ 학년: $B=-.57$ ), (중학교 1 학년: $B$
$=-.54)$ J에 부적 영향을 미쳤다. 이는 아동의 또래유능성이 높 을수록 해당 시기에 사회적 위축 수준이 낮음을 의미한다. 지 연효과 또한 4학년의 또래유능성은 6학년에서의 사회적 위축 $(B=-.09)$ 에, 6 학년의 또래유능성은 중학교 1 학년에서의 사회 적 위축 $(B=-.23)$ 에 부적인 영향을 미치는 것으로 나타났는데, 이는 이전 시기의 또래유능성의 수준이 높으면 이후 시기에서 
사회적 위축의 수준이 높지 않음을 의미한다.

\section{논의 및 결론}

본 연구에서는 한국아동.청소년패널 종단자료를 사용하여 초 등학교 4학년에서 중학교 1학년까지 아동의 사회적 위축 발 달궤적을 탐색하고, 발달궤적에 부모의 과잉간섭 양육행동이 미치는 영향과 또래유능성의 동시 효과와 지연 효과를 검증하 였다. 연구문제에 따른 주요 결과들을 중심으로 논의하고, 결 과에 따른 시사점을 서술하면 다음과 같다.

첫째, 초등학교 4학년에서 중학교 1학년까지 학년의 증가 에 따라 사회적 위축은 유의하게 증가하는 것으로 나타났으 며, 이는 아동 후기에서 초기 청소년기 동안 사회적 위축이 증 가하는 경향으로 나타난 선행연구 결과(Booth-LaForce et al., 2012; Miers, Blöte, Heyne, \& Westenberg, 2014)와 일치하는 것 이다. 이러한 결과는 초등학교 중기에서 중학교 초기로의 전 환기의 발달적 특성을 고려하여 해석해볼 수 있다. 즉, 아동은 사춘기를 겪는 동안 신체적, 심리적으로 급격한 변화를 경험 할 뿐 아니라 상급 학교로 진학하면서 새로운 또래와의 만남 등 다양한 환경적 도전을 경험할 수 있다. 이로 인해 타인과의 관계에서 다소 소극적으로 반응하고, 사회적 관계 자체를 어 렵게 느낄 수 있다(Yoo, 2007). 이러한 결과는 사회적으로 위축 된 아동들을 조기에 발견하여 면밀히 관찰함으로써 초등학교 중기에서 중학교 초기로의 전환기 동안 시간의 흐름에 따라 사회적 위축이 악화되는 것을 예방하기 위한 개입과 지원을 가능하면 조기에 제공하는 것이 필요함을 강력히 시사하는 것 이다. 구체적인 개입 방안은 본 연구에서 예측 변인으로 다루 어졌던 부모의 과잉간섭 양육행동, 또래유능성 등을 고려하여 제안해볼 수 있을 것이다.

둘째, 사회적 위축 발달궤적에 미치는 예측 변인의 영향을 분석한 결과, 부모의 과잉간섭은 사회적 위축의 초기값과 변 화율 모두에 유의한 영향을 미치는 것으로 나타났다. 부모가 자녀의 생활에 지나치게 관여하고 제재를 가할수록 사회적 위 축 수준이 높은 것으로 나타난 본 연구 결과는 과잉간섭 행동 이 사회적 위축의 주요 예측요인임을 주장한 선행연구 결과 와 일치하는 것이다(Coplan et al., 2008; Jeon \& Kim, 2016; Kiel, Premo, \& Buss, 2016). 이러한 결과는 부모가 아동에게 과하게 간섭을 하면 아동이 자기의 능력을 불신하고, 자신감이 낮아지 는 등 자신에 대해 부정적인 시각을 갖게 되며, 이는 아동으로 하여금 사회적 상황에서 독립적으로 기능하는 것과 관련된 불
안함과 긴장감을 야기함으로써 사회적 상황에서 철회하는 모 습을 보이게 되는 것으로 해석해볼 수 있다. 특히, 최근 한국 사 회에서는 지나친 입시경쟁이나 교육열로 인해 부모들은 자녀 에게 학업적 성취에 과도하게 가치를 부여하면서 자녀가 학업 에 몰두할 수 있게끔 자녀의 모든 생활 스케줄을 대신 관리하 거나 자녀의 흥미나 자율성을 고려하지 않고 일방적으로 자녀 와 관련된 중요한 의사결정을 내리는 경향이 있다. 비록 부모 들은 이와 같은 과잉간섭적인 행동들을 자녀에게 도움을 주기 위한 의도로 행하지만, 오히려 사회적 위축이라는 문제를 야기 할 수 있다는 사실을 주지할 필요가 있다. 또한, 이 시기에는 부 모가 자녀의 자율성을 격려함으로써 자녀의 자신감을 향상시 킴으로써 아동이 사회적 관계를 형성하고 유지할 때 불안해하 지 않고 보다 적극적이고 행동할 수 있게 도울 수 있을 것이다.

한편, 부모의 과잉간섭 행동은 사회적 위축의 변화율에 부 적 영향을 미친 것으로 나타나 전반적으로 아동의 사회적 위 축은 시간의 흐름에 따라 증가하고 있지만 초등학교 4학년 때 부모가 자녀의 생활에 관여하고 간섭할수록 아동의 사회적 위 축은 서서히 증가함을 보여주었다. 이는 4 학년 때 부모의 과잉 간섭 수준이 높은 아동의 경우 사회적 위축의 초기값이 유의 하게 높았고, 사회적 위축의 초기값이 높을수록 사회적 위축 이 느리게 증가하는 본 연구 결과를 반영하는 것이라 할 수 있 다. 4 학년 시기에 부모가 자녀의 생활에 지나치게 간섭하고 관 여를 한 경우, 아동의 사회적 위축이 이미 높은 수준에 있었고 따라서 이후의 변화율은 상대적으로 크지 않았음을 의미한다.

셋째, 또 다른 예측 변인인 또래유능성의 경우 각 시기에 서 로 다른 또래와 상호작용한다는 것을 근거로 세 시기의 측정 치를 모두 포함시켜서 분석하였고, 그 결과 해당 시기의 또래 유능성 수준이 높을수록 사회적 위축의 수준이 낮았으며, 이 러한 경향은 세 시기에 모두 동일하게 나타났다. 이는 또래 관 계의 형성과 유지에 필요한 기술과 능력이 부족한 아동들은 사회적 위축을 경험할 가능성이 크다는 기존 연구결과(Farmer \& Cadwallader, 2000; Kingery et al., 2010; J. Y. Park, Kang, Heo, $\&$ Jung, 2010; Wu et al., 2010)와 일치하는 것이다. 이러한 결과 는 또래에게 자신의 의견을 표현하거나 또래의 요구를 이해하 는 데 어려움이 있고, 또래의 반응에 적절히 대처하지 못하는 등 또래 관계에서 필요한 기술과 능력이 부족한 아동의 경우 부정적인 또래 상호작용을 경험하게 되고, 결과적으로 아동의 사회적 위축을 야기할 수 있음을 보여주는 것이다. 또한, 또래 유능성의 지연효과를 분석한 결과 초등학교 4 학년의 또래유 능성은 초등학교 6 학년과 중학교 1학년의 사회적 위축에, 초 등학교 6학년의 또래유능성은 중학교 1학년의 사회적 위축에 
유의한 부적 영향을 미치는 것으로 나타났다. 이러한 결과는 초등학교 중기와 초등학교 후기 중 어느 한 시기에서라도 또래 유능성이 낮으면 해당 시기 뿐 아니라 이후 시기의 사회적 위 축에도 영향을 미치기 때문에 전환기 동안 사회적 위축을 예방 하고 감소시키기 위해서 매 시기마다 또래유능성 수준이 낮아 지지 않게 지속적으로 관심을 갖고 개입해야 함을 의미한다.

사회적 위축에 미치는 또래유능성의 동시효과와 지연효과 가 전환기 동안 모두 유의했다는 본 연구 결과는 사회적 위축 을 감소시키기 위해서 또래 관계 차원에서 또래 관계를 형성 하고 유지하는 기술을 강화하는 것이 효과적인 방법 중 하나 가 될 수 있음을 시사하고 있다. 아동의 또래유능성을 증진시 키기 위한 방법은 크게 개인적인 차원과 학급 차원으로 구분 해서 접근해볼 수 있다. 우선, 개인적 차원에서는 개별 아동에 게 또래 관계를 긍정적으로 형성하고 유지하는 데 필요한 구 체적인 기술을 습득할 수 있게 돕는 것이 필요하다. 특히 초등 학교 고학년과 청소년기의 경우, 교사나 부모가 직접 개입을 하여 아동이 또래 관계를 맺고 유지할 수 있도록 하는 것이 도 움이 되는 저학년 시기와는 달리 아동이 독립적으로 또래 관 계를 형성하고 유지할 수 있도록 하는 것이 강조되는 시기이 다. 따라서 개인적 차원에서 초등학교 중기, 후기, 중학교 초 기동안 아동의 또래유능성을 높이기 위해 아동이 스스로 또 래 관계를 형성하고 이를 지속시킬 수 있도록 도와줄 수 있다. 이를 위해 아동의 관심 분야와 관련된 모임이나 수업에 참여 시킴으로써 아동 자신과 비슷한 흥미를 가진 또래들과 관심사 를 공유하거나 대화하는 등 자연스럽게 상호작용을 시작하는 기회를 갖게 할 수 있다. 또한, 또래들이 일반적으로 관심 갖고 있는 분야나 활동에 대한 정보를 아동에게 제공함으로써 아동 이 또래 집단에 잘 다가가고, 어울릴 수 있게 도와줄 수 있다.

다음으로, 학급 차원의 중재 방안은 크게 또래와의 협력을 통해 공동 목표에 도달하게 하는 집단 활동과 같이 또래들과 의 적극적인 상호작용이 요구되는 활동을 실시하는 것과 교실 내 또래들이 돌아가면서 리더의 경험을 갖게 하는 것으로 나 누어 살펴볼 수 있다. 먼저, 공동의 목표를 위해 또래와의 협동 이 필요한 활동을 함으로써 아동은 또래와 협력하는 방법과 또래와의 의견 불일치나 갈등에 대한 대처 방법들을 배울 수 있다. 이에 더해 협동 활동에서 필요한 타인의 욕구와 감정을 이해하는 능력과 자기 정서를 적절하게 표현하는 능력을 배우 는 기회를 가질 수 있다. 특히, 사회적으로 위축된 아동들은 이 러한 집단 활동을 통해 또래와의 상호작용 경험을 통해 또래 관계에서 일어나는 다양한 문제에 대한 해결책을 습득하고 적 용해봄으로써 또래유능성이 길러질 수 있다. 실제로 Battistich
(2003)의 연구에서 교실 내에서 공동 목표를 위해 협동하는 기 회가 주어진 집단은 그렇지 않은 집단보다 또래유능성이 높았 던 결과가 이를 뒷받침한다. 다음으로, 또래유능성 수준을 높 이기 위해 학급 내에서 아동들이 돌아가며 리더의 경험을 갖 게 하는 것이 도움이 될 수 있다. 더욱이 스스로 리더가 될 기 회를 갖기 어려운 사회적으로 위축된 아동은 리더 역할을 통 해 학급 내에서의 또래 갈등을 중재하는 등 또래 관계에서 적 극성과 주도성을 갖는 연습을 함으로써 또래 관계에서의 자신 감을 향상시키고 결과적으로 또래유능성을 증진시킬 수 있다.

마지막으로 본 연구에 대한 제한점을 밝히고, 후속 연구를 위한 제언을 하면 다음과 같다. 첫째, 본 연구에서는 사회적 위 축을 다양한 사회적 상황에서 수줍음을 느끼고 우울해지고 그 러한 상황을 피하는 경향이나 행동으로 정의된 단일 구인으로 서 연구하였다. 최근에는 단일한 구인으로서 사회적 위축에 접근하는 관점 이외에도 사회적 위축의 하위 유형을 구분해야 한다는 주장도 제기되고 있다. 예를 들어, Asendorpf (1990)의 모델에서 제시하는 바와 같이 사회적 위축은 수줍음, 회피, 사 회적 무관심/비사교성 등으로 구분해서 보아야 한다는 견해 가 있다(Bowker \& Raja, 2011; Coplan et al., 2013). 이러한 관점 을 고려해본다면 사회적 위축의 하위 유형들은 서로 다른 발 달궤적을 보일 수 있으므로 추후 연구에서는 사회적 위축의 하위 유형을 구분하여 전환기 동안의 발달궤적을 보는 것도 흥미로운 과제가 될 것으로 사료된다.

둘째, 본 연구에서는 초등학교 중기, 후기, 중학교 초기를 통해 전환기 동안 사회적 위축의 발달궤적을 알아보고, 부모 의 과잉간섭과 또래유능성의 영향을 검증하기 위해 한국아동. 청소년패널 데이터를 이용하였다. 각 시기에 측정된 변인이 동일하지 않을 수 있다는 패널 데이터의 특성상 본 연구에 포 함된 변인의 경우에도 세 개의 측정 시기에 모든 변인을 다 분 석에 포함시킬 수 없었다. 초등학교 3학년의 경우 4학년 이후 시기와는 달리 부모 보고로 측정되었기 때문에 초등학교 중 기, 후기, 중학교 초기를 대표하는 시기로 초등학교 4학년, 6 학년, 중학교 1학년 자료를 선택하여 분석하였다. 선택된 이 시기가 본 연구에서 검증하고자 하였던 발달 단계를 잘 대표 해주었다고 판단되었다. 만약, 가용한 모든 데이터가 있어서 초등학교 3학년부터 중학교 1학년까지 모두 포함하여 분석할 수 있다면 아동기에서 초기 청소년기로의 발달궤적을 더 잘 이해할 수 있을 것이라 사료된다.

패널 데이터 사용과 관련된 또 다른 제한점으로 부모의 과 잉간섭에 대한 문제를 들 수 있다. 본 연구에서는 부모의 과잉 간섭이 시간의 흐름에 따라 안정적인 개념이라는 선행 연구 
자들의 주장(Forehand \& Jones, 2002; Huh, 2004; Loeber et al., 2000)을 근거로 초등학교 4학년 시기의 과잉간섭이 사회적 위 축의 발달에 미치는 종단적 영향을 검증하였다. 그러나 과잉간 섭 양육행동은 자녀 연령 또는 부모에 대한 자녀의 태도나 행 동에 따라 달라질 수 있음을 완전히 배제할 수 없다는 점 때문 에 각 시기별 분석도 의미 있을 수 있다고 판단하였으나 본 연 구에서 사용한 패널데이터에서는 나머지 시기의 자료를 얻을 수 없었다. 따라서 추후 연구에서 사회적 위축이 측정된 모든 시기의 과잉간섭 자료를 포함하여 분석한다면 전환기 동안 사 회적 위축의 변화에 미치는 과잉간섭의 영향을 규명하는 데 있 어 보다 구체적인 정보를 제시해줄 수 있을 것으로 기대된다.

그럼에도 불구하고, 본 연구가 지니는 시사점과 의의는 다 음과 같다. 첫째, 기존의 연구들은 대부분 횡단 자료를 이용해 서 특정 시점에서의 부모의 과잉간섭과 또래유능성이 사회적 위축에 미치는 영향을 알아보았으며, 그 결과 과잉간섭과 또 래유능성이 사회적 위축에 영향을 미치는 것으로 나타났다. 하지만 사회적 위축의 변화 양상과 사회적 위축의 발달궤적에 대한 과잉간섭과 또래유능성의 영향을 알아보는 데는 한계가 있었다. 이러한 측면에서 본 연구 결과를 통해 사회적 위축이 전반적으로 증가하는 것을 알 수 있었다는 점에서 의의가 있 다. 이는 전환기의 특성과도 무관하지 않을 것이며, 이러한 결 과는 사회적 위축이 높았던 아동들이 더 이상 사회적 위축이 증가하지 않게 조기에 개입을 해야 함을 시사하였다.

둘째, 과잉간섭의 종단적 영향을 검증한 결과, 4 학년 시기 에 부모의 과잉간섭이 높을수록 아동의 사회적 위축 수준이 높은 경향이 있었고, 이러한 경향은 중학교 1학년 시기까지 지 속되는 것으로 나타났다. 부모가 자녀에게 독립성과 자율성을 격려하고 이를 촉진하는 것이 초기 청소년기에 들어서면서 중 요한 과업으로 인식하는 경향이 있지만, 본 연구 결과는 더 이 른 시기부터 지나친 관여와 간섭을 지양하고 아동의 자율성을 보장하는 것이 필요함을 보여주는 경험적 증거를 제시했다는 점에서 의의가 있다. 마찬가지로 사회적 위축에 대한 또래유 능성의 영향 역시 동시효과뿐 아니라 지연효과가 있음을 밝힘 으로써 조기에 안정적인 또래 관계를 맺고, 상호작용 기술을 습득하도록 돕는 것이 아동기에서 초기 청소년기로의 전환기 동안 사회적 위축을 예방하는 효과적인 방안이 될 수 있음을 보여주었다는 점에서 본 연구의 가치를 찾을 수 있다. 이와 같 이 본 연구는 초등학생의 사회적 위축의 감소를 위해 부모와 또래 관계 차원에서 시기적절하게 어떠한 노력을 할 수 있을 지에 대한 정보를 제공했다는 점에서 본 연구의 의의가 있다.

\section{Notes}

This article was presented as a poster at the 2018 Annual Spring Conference of the Korean Association of Child Studies.

\section{Conflict of Interest}

No potential conflict of interest relevant to this article was reported.

\section{References}

\section{In English}

Battistich, V. (2003). Effects of a school-based program to enhance prosocial development on children's peer relations and social adjustment. Journal of Research in Character Education, 1(1), 1-17.

Booth-LaForce, C., Oh, W., Kennedy, A. E., Rubin, K. H., RoseKrasnor, L., \& Laursen, B. (2012). Parent and peer links to trajectories of anxious withdrawal from grades 5 to 8 . Journal of Clinical Child \& Adolescent Psychology, 41(2), 138-149. doi:10.1080/15374416.2012.651995

Bornstein, M. H., Hahn, C.-S, \& Haynes, O. M. (2010). Social competence, externalizing, and internalizing behavioral adjustment from early childhood through early adolescence: Developmental cascades. Development andPsychopathology, 22(4), 717-735. doi:10.1017/S0954579410000416

Bowker, J. C., \& Raja, R. (2011). Social withdrawal subtypes during early adolescence in India. Journal of Abnormal Child Psychology, 39(2), 201-212. doi:10.1007/s10802010-9461-7

Bowker, J., Rubin, K. H., \& Coplan, R. J. (2012). Social withdrawal in adolescence. In R. J. R. Levesque (Ed.), Encyclopedia of adolescence (pp. 2817-2824). New York: Springer.

Burgess, K., Rubin, K., Cheah, C., \& Nelson, L. (2001). Socially withdrawn children: Parenting and parent-child relationships. In R. Crozier, \& L. E. Alden (Eds.), The self, shyness and social anxiety: A handbook of concepts, research, and interventions. New York: Wiley.

Chan, G. H. (2015). The effect of life-course transitions on delinquent behavior among youth in social withdrawal situation. Deviant Behavior, 36(12), 935-955. doi:10.1080/ 01639625.2014 .977181 
Coplan, R. J., Arbeau, K. A., \& Armer, M. (2008). Don't fret, be supportive! Maternal characteristics linking child shyness to psychosocial and school adjustment in kindergarten. Journal of Abnormal Child Psychology, 36(3), 359-371. doi:10.1007/s10802-007-9183-7

Coplan, R. J., \& Armer, M. (2007). A “multitude” of solitude: A closer look at social withdrawal and nonsocial play in early childhood. Child Development Perspectives, 1(1), 26-32. doi:10.1111/j.1750-8606.2007.00006.x

Coplan, R. J., Rose-Krasnor, L., Weeks, M., Kingsbury, A., Kingsbury, M., \& Bullock, A. (2013). Alone is a crowd: Social motivations, social withdrawal, and socioemotional functioning in later childhood. Developmental Psychology, 49(5), 861-875. doi:10.1037/a0028861

Farmer, T. W., \& Cadwallader, T. W. (2000). Social interactions and peer support for problem behavior. Preventing School Failure: Alternative Education for Children and Youth, 44(3), 105-109. doi:10.1080/10459880009599791

Forehand, R., \& Jones, D. J. (2002). The stability of parenting: A longitudinal analysis of inner-city African-American mothers. Journal of Child and Family Studies, 11(4), 455467. doi:10.1023/A:1020935525335

Goodwin, R. D., Fergusson, D. M., \& Horwood, L. J. (2004). Early anxious/withdrawn behaviors predict later internalizing disorders. Journal of Child Psychology and Psychiatry, 45(4), 874-883. doi:10.1111/j.1469-7610.2004.00279.x

Keith, T. Z. (2015). Multiple Regression and Beyond (2nd ed.). New York: Taylor \& Francis.

Kiel, E. J., Premo, J. E., \& Buss, K. A. (2016). Gender moderates the progression from fearful temperament to social withdrawal through protective parenting: Gender and fearful temperament. Social Development, 25(2), 235-255. doi:10.1111/sode.12145

Kingery, J. N., Erdley, C. A., Marshall, K. C., Whitaker, K. G., \& Reuter, T. R. (2010). Peer experiences of anxious and socially withdrawn youth: An integrative review of the developmental and clinical literature. Clinical Child and Family Psychology Review, 13(1), 91-128. doi:10.1007/ s10567-009-0063-2

Loeber, R., Drinkwater, M., Yin, Y., Anderson, S. J., Schmidt, L. C., $\&$ Crawford, A. (2000). Stability of family interaction from ages 6 to 18. Journal of Abnormal Child Psychology, 28(4), 353-369. doi:10.1023/A:1005169026208

Miers, A. C., Blöte, A. W., Heyne, D. A., \& Westenberg, P. M. (2014). Developmental pathways of social avoidance across adolescence: The role of social anxiety and negative cognition. Journal of Anxiety Disorders, 28(8), 787-794. doi:10.1016/j.janxdis.2014.09.008

Mplus (Version 6.11). [Computer software]. Los Angeles, CA: Muthén \& Muthén.
Nelson, L. J. (2013). Going it alone: Comparing subtypes of withdrawal on indices of adjustment and maladjustment in emerging adulthood: Social withdrawal in emerging adulthood. Social Development, 22(3), 522-538. doi:10.1111/ j.1467-9507.2012.00671.x

Oh, W., Rubin, K. H., Bowker, J. C., Booth-LaForce, C., RoseKrasnor, L., \& Laursen, B. (2008). Trajectories of social withdrawal middle childhood to early adolescence. Journal of Abnormal Child Psychology, 36(40), 553-566. doi:10.1007/ s10802-007-9199-z

Prior, M., Smart, D., Sanson, A., \& Oberklaid, F. (2000). Does shy-inhibited temperament in childhood lead to anxiety problems in adolescence?. Journal of the American Academy of Child and Adolescent Psychiatry, 39(4), 461-468. doi:10.1097/00004583-200004000-00015

Rubin, K., Bowker, J., \& Kennedy, A. (2009). Avoiding and withdrawing from the peer group. In K. H. Rubin, W. M. Bukowski, \& B. Laursen (Eds.), Handbook of peer interactions relationships, and groups (pp. 303-321). Hoboken, New York: Guilford Press.

Rubin, K., Coplan, R., \& Bowker, J. (2009). Social withdrawal in childhood. Annual review of Psychology, 60, 141-172. doi:10.1146/annurev.psych.60.110707.163642

Schwartz, C., Snidman, N., \& Kagan, J. (1999). Adolescent social anxiety as an outcome of inhibited temperament in childhood. Journal of the American Academy of Child \& Adolescent Psychiatry, 38(8), 1008-1015. doi:10.1097/00004583199908000-00017

Segrin, C., \& Flora, J. (2000). Poor social skills are a vulnerability factor in the development of psychosocial problems. Human Communication Research, 26(3), 489-514. doi:10.1093/hcr/26.3.489

Shell, M., Gazelle, H., \& Faldowski, R. (2014). Anxious solitude and the middle school transition: A diathesis $\mathrm{x}$ stress model of peer exclusion and victimization trajectories. Developmental Psychology, 50(5), 1569-1583. doi:10.1037/ a0035528

Shin, N., Vaughn, B. E., Kim, M., Krzysik, L., Bost, K. K., McBride, B., . . . Coppola, G. (2011). Longitudinal analyses of a hierarchical model of peer social competence for preschool children: Structural fidelity and external correlates. Merrill-Palmer Quarterly, 57(1), 73-103.

Sterba, S. K., Prinstein, M. J., \& Cox, M. J. (2007). Trajectories of internalizing problems across childhood: Heterogeneity, external validity, and gender differences. Development and Psychopathology, 19(2), 345-366. doi:10.1017/ S0954579407070174

Wu, C., Lo, Y., Feng, F., \& Lo, Y. (2010). Social skills training for taiwanese students at risk for emotional and behavioral disorders. Journal of Emotional and Behavioral Disorders, 16, 
1-16. doi:10.1177/1063426609344605

Zhang, W., Wei, X., Ji, L., Chen, L., \& Deater-Deckard, K. (2017). Reconsidering parenting in Chinese culture: Subtypes, stability, and change of maternal parenting style during early adolescence. Journal of Youth and Adolescence, 1-20. doi:10.1007/s10964-017-0664-x

\section{In Korean}

Huh, M. (2004). A study for the development and validation of an inventory for parenting behavior perceived by adolescents. The Korea Journal of Youth Counseling, 12(2), 170-189.

Jeon, R.-Y., \& Kim, H. H. (2016). The effects of inconsistent parenting and intrusive parenting on early adolescents' social withdrawal: The mediating effect of early adolescents' self-esteem. Journal of the Korea Institute of Youth Facility and Environment, 14(2), 57-67.

Kang, K.-A., Kim, S.-J., Song, M.-K., Sim, S., \& Kim, S.H. (2007). Development of an instrument to measure meaning of life (MOL) for higher grade primary school children. Child Health Nursing Research, 13(3), 308-317.

Kim, S.-H. \& Kim, K.-Y. (1998). Development of behavior problem scale for children and adolescence. Journal of Korean Home Management Association, 16(4), 155-166.

Min, B. S. (1991). The influence of school life adjustment and selfconcept on academic achievement (Master's thesis). Retrieved from http://www.riss.kr/link?id=T2167733

Min, W.-H., \& Son, S.-O. (2017). Trajectories of social withdrawal on negative peer relations: Moderating effects of parental monitoring. Journal of Future Oriented Youth Society, 14(1), 75-99.

National Youth Policy Institute. (2010-2016). Korean children and youth panel survey [Data file and code book]. Retrieved from NYPI website: http://archive.nypi.re.kr/
Park, J. Y., Kang, S. Y., Heo, S. Y., \& Jung J. E. (2010). A review of the literature on social skill interventions for children and adolescents with emotional and behavioral difficulties. The Korean Society of Emotional and Behavioral Disorders, 26(4), 43-72.

Park. J. H., \& Rhee, U. H. (2001a). Development of a peer competence scale for preschool children. Family and Environment Research, 39(1), 221-232.

Park. J. H., \& Rhee, U. H. (2001b). Children's peer competence: Relationships to maternal parenting goals, parenting behaviors, and management strategies. Korean Journal of Child Studies, 22(4), 1-15.

Shim, S. (2010). Behavioral and relational correlated of low selfperceived competence in young children. Journal of Korean Council for Children \& Rights, 14(2), 271-292.

Shin, M., Jeon, S. H., \& Yoo, M. S. (2012). Analysis of the structural relationship between social relationships, self Esteem, life satisfaction, and school adjustment in early adolescents. Korean Journal of Child Studies, 33(1), 81-92.

Yoo, S. H. (2007). Student expectations and perceptions of the transition from elementary to middle school. The Journal of Elementary Education, 20(1), 355-375.

\section{ORCID}

Yoon Kyung Kim

Ju Hee Park http://orcid.org/0000-0002-6431-1225

http://orcid.org/0000-0003-3031-0272
Received April 30, 2018

Revision received June 22, 2018

Accepted August 3, 2018 